\title{
ALEXIS DE TOCQUEVILLE Y SU VIGENCIA HOY ${ }^{1}$
}

\author{
DEMETRIO VELASCO \\ Universidad de Deusto
}

\begin{abstract}
RESUMEN: Pocos autores han sido tan visitados y tenidos en cuenta entre los clásicos del pensamiento político como Alexis de Tocqueville. Sus aportaciones para entender algunas de las patologías que aquejan a nuestras sociedades, así como la identificación de algunos recursos para corregirlas, lo convierten en un autor de primera magnitud. El presente texto centra la atención sobre los argumentos críticos de este autor frente al liberalismo doctrinario de su momento, trazando una continuidad ideológica diacrónica que sitúa en casi idénticas coordenadas el actual proceso de globalización capitaneada por el neoliberalismo. En ese contexto de urgencia social se despliegan argumentos en torno a la libertad, la desigualdad, la religión o la violencia de sorprendente actualidad y con una clarísima derivada de orden práctico.
\end{abstract}

PALABRAS CLAVE: liberalismo doctrinario, libertad, desigualdad, democracia, religión.

\section{Alexis de Tocqueville and his actual validity}

ABSTRACT: Only few authors have been so well considered and taken into account among the classics of political thought as Alexis de Tocqueville. His contributions to understand some of the pathologies affecting our societies, as well as the identification of a set of resources to correct and health them, makes of him an author of outstanding significance. This paper focusses on his critical arguments about the doctrinarian liberalism of his time, sketching an ideological diachronic continuity that locates almost in the same coordinates the present globalization process led by neoliberalism. In this context of social urgency arguments about freedom, inequality, religion or violence are shown with a surprising topicality and with a clear derivate of practical order.

KEY WORDS: doctrinarian liberalism, freedom, inequality, democracy, religion.

Tocqueville es, hoy, uno de los clásicos del pensamiento político y social más citados. Se considera que su obra se hace imprescindible, no sólo cuando se quiere comprender la patológica deriva histórica de nuestras sociedades modernas, sino, sobre todo, cuando se quieren buscar los recursos sociopolíticos y morales que nos permitan encontrar soluciones razonables a dicha deriva ${ }^{2}$.

1 El presente texto se enmarca dentro del marco del Proyecto de Investigación Poder Público y Empresa en un contexto multinivel y transnacional (Gobierno Vasco IT607-13 / Deusto R2013) de la Facultad de Derecho de la Universidad de Deusto.

2 En América ha sido un autor más citado que los Padres Fundadores, exceptuando Jefferson (por su Declaración de Independencia). Presidentes, políticos, Congreso, medios, lo citan sin cesar. Se han creado asociaciones y fundaciones con su nombre... y, recientemente, hasta corrientes de pensamiento como los «neotocquevillianos» (caso de Putnam, R. y su obra Bowling Alone: The Collapse and Revival of American Community (2000), desarrollo del artículo publicado en 1995, que de alguna forma reproducen la obra de D. Riesman que, en los años 50, escribió inspirado en Tocqueville The Lonley Crowd: A Study of the American Character, 1953. Incluso, personajes como M. THATcher, N. GINGRich, o H. SсHмidT, han escrito sobre él. En Francia la figura de Tocqueville queda casi silenciada desde 1870 hasta la década de los 
Pero lo paradójico de Tocqueville es que no siempre ni en todos los lugares ha sido tenido tan favorablemente en cuenta, como ha sido el caso de Europa y especialmente el de Francia, su patria de nacimiento. Quienes, hace ya más de cuarenta años, estudiábamos en España la historia de las ideas y formas políticas de occidente, lo hacíamos con un texto canónico como era el de G. Sabine. Historia de la Teoría Política, que, desde 1937 en que se publicó, ha tenido algunas reediciones e innumerables reimpresiones, siendo utilizado como el indiscutible texto de referencia. Este texto no cita ni una sola vez a A. de Tocqueville.

Dejando ahora de lado la complejidad de las causas que se aducen para explicar esta sorprendente anomalía y a las que me he referido en otro lugar ${ }^{3}$, creo que en las mismas razones que se aducen para explicar el ostracismo al que fue condenado durante tanto tiempo, así como su posterior recuperación, hay ya algunas lecciones importantes que aprender para nuestros días. Unas son las relacionadas con la figura personal de Tocqueville, con su biografía personal e intelectual. Me refiero, sobre todo, a dos características significativas y relevantes para un intelectual y político, como fue nuestro autor: la independencia y la originalidad, que lo convirtieron en un personaje incómodo para casi todos y difícil de encajar ideológica y políticamente ${ }^{4}$; hay otras razones que están relacionadas

cincuenta del siglo xx, en que el historiador marxista G. LeFEBVRe (Introducción a una nueva traducción de El Antiguo Régimen y la Revolución (ARR), de 1952, y el sociólogo R. ARON (Las grandes etapas del movimiento sociológico, 1955,), subrayan el significado y vigencia de su obra. Más tarde, Furet y su reinterpretación de la Revolución Francesa desde Tocqueville (cfr. Kahan, A. S., Alexis de Tocqueville. Maior Conservative and Libertarian Thinkers. Ed. J. Meadowcroft, New York/London, 2010)

3 Ver Velasco, D. «Tocqueville (1805-1859), dos siglos después» Estudios de Deusto. Vol. 53/1, enero-junio 2005, 183-250.

4 Como muestra de su independencia precoz respecto a partidos y medio familiar está su rechazo a entrar en la Administración: «Siempre he tenido, bajo todos los regímenes (sin excepción alguna) la mayor repugnancia a entrar en la Administración; y lo que en ella he visto, examinándola de cerca, ha aumentado todavía más esta repugnancia y, en general y a priori, siento (salvo casos particulares) poca simpatía por quienes hacen carrera en ella. He advertido que, para triunfar en ella, había que mostrar mucha debilidad y obsequiosidad con los que os mandaban, y mucha doblez y violencia sobre quienes uno mismo mandaba. En Francia, la Administración apenas actúa por el interés general del país, sino casi siempre por el interés particular de quienes gobiernan. Y todo aquel que no esté dispuesto a sacrificar sin cesar el primero de estos intereses al otro no tiene ninguna esperanza de ascender. (...) Siempre, pues, he sentido una repugnancia invencible por la Administración; y, aunque en la carrera judicial haya habido muchas cosas que no me gustaban, no he dudado en abrazarla, persuadido de que de todas las carreras civiles era la única que daba independencia frente a los poderes pasajeros que se suceden en nuestro país; la única que permite, a la vez, ser funcionario y seguir siendo uno mismo». (carta a su sobrino preferido Hubert de Tocqueville, 12/01/1854). Esta es la razón por la que acepta ser juez auditor en vez de subprefecto y sigue el ejemplo de su ancestro materno Malesherbes en vez del de su padre. Logra serlo en Versalles, donde éste es prefecto desde 1826. Era un puesto no remunerado pero que permitía una buena formación jurídica e histórica; como muestra de su originalidad: «El fracaso político de Tocqueville no se explica solo por su umbría e inquietante independencia, sino también por la originalidad de su pensamiento. Monárquico, pero, como Chateaubriand o Mme de Stäel, solo ama de la monarquía lo que es anterior al absolutismo (bien la temperada 
con los contextos: el contexto histórico-ideológico de la época de Tocqueville y el contexto de su reciente recuperación, en la segunda mitad del siglo xx.

En primer lugar, respecto a las diversas corrientes ideológicas que se daban en el contexto ideológico y político de su época, Tocqueville demostró tanto su independencia como su originalidad y se distanció de ellas, como lo podremos comprobar al referirnos al liberalismo doctrinario. Para hacernos una composición de lugar, debemos recordar el mapa de las principales corrientes ideológicas del liberalismo francés del momento. Aunque el liberalismo francés, presenta unos rasgos comunes como son la oposición al absolutismo y a la sociedad estamental; la asunción de los principios iniciales de la revolución y el rechazo de sus perversiones, sobre las que reflexiona, y la conciencia de haber entrado en un mundo nuevo que exige instituciones políticas nuevas, es imprescindible señalar su polivalencia y polisemia ${ }^{5}$. La corriente del liberalismo doctrinario me parece especialmente relevante tanto por lo que a la definición del pensamiento de Tocqueville se refiere, como por la gran vigencia histórica que ha tenido, especialmente en países como Francia y España. En mi opinión, creo que se puede calificar de «liberalismo doctrinario» a la pervivencia secular de un «materialismo histórico reaccionario» que se ha hecho hegemónico

a lo Montesquieu o la controlada por los estados generales y por una aristocracia orgullosa de su independencia). Republicano en 1848, favorable al sufragio universal, pero con tal de que sea guiada por una élite de notables. Es demasiado aristócrata para amar la cultura democrática de masas, de la que es el analista más agudo. Pero es demasiado demócrata para aceptar un mundo que fuera desigualitario hasta el punto de privar a los individuos de su autonomía y de su capacidad para participar en la responsabilidad de los asuntos comunes. Proclama que no hay otro futuro posible que la democracia, pero para añadir enseguida que la democracia no es necesariamente liberal. "Liberal de una nueva especie", alimenta su pensamiento de la minuciosa observación del mundo de su tiempo, elabora su teoría lo más cerca posible de los acontecimientos, y su obra no se convierte en menos "clásica" por trascender las circunstancias de su nacimiento. Él mismo fue consciente de deber su genio a la coherencia de una vida y de un pensamiento totalmente entregados a la educación de la democracia». Cfr. Mélonio, F., Alexis de Tocqueville (2006), 82-83.

5 Véase dicho mapa ideológico en D. Velasco, «Tocqueville (1805-1859), dos siglos después», 187-189. Autores como A. de Tocqueville o Lamennais no son fáciles de clasificar en este convencional mapa de corrientes liberales de la época (burgueses orleanistas de conveniencia, «ideólogos», doctrinarios, jóvenes románticos, demócratas). Lamennais porque a lo largo de su vida va pasando por etapas muy diferentes: teocracia, liberalismo y democracia. Tocqueville porque es la figura más compleja y polivalente del liberalismo francés. Recojo un significativo texto con el que F. Mélonio concluye su estudio sobre el liberal Tocqueville: «Libéral, le mot n'a d'ailleurs que la séduction du flou. On n'est pas libéral tout court et sans déterminants. On est libéral autoritaire, libéral conservateur, libéral monarchiste, libéral républicain, libéral démocrate, sagement libéral, «libéral d’une espèce nouvelle» tel Tocqueville, voire sous la Troisiéme République, «libérátre» ou «libéroufle»... Il y a des pratiques libérales, des sensibilités libérales, des générations libérales qui furent de "gauche» ou de "droite», et parfois, l'áge aidant, les deux successivement mais pas un libéralisme français. L'ceuvre de Tocqueville nous importe donc moins par la lignée dans laquelle on l'insère que par son exotisme. Aristocrate d'instinct et démocrate de raison, au carrefour des deux cultures française et américaine, Tocqueville a été le refoulé de notre tradition démocratique». (Melonio, F., Tocqueville et les Françai,.1993, Paris,. Aubier: 304). 
en nuestras sociedades y que, hoy, en el actual proceso de globalización economicista se sigue imponiendo como capitalismo neoliberal. Intento explicar esta afirmación haciendo una descripción de los aspectos más significativos de dicho liberalismo.

\section{El LibERALISMO DOCTRINARIO ${ }^{6}$}

La burguesía hegemónica que controló el proceso revolucionario y que fue la beneficiaria neta de sus frutos, especialmente del «mayor y más rápido transfert de propiedad que haya conocido nuestra historia», según han afirmado Furet y Richet, no sólo sofocó aquellos proyectos revolucionarios que tenían mayor virtualidad emancipadora y democratizadora, sino que clausuró la Revolución, condenando como ilegítimo cualquier intento de continuarla. La contundente defensa del derecho de propiedad, del sufragio censitario y de todos los derechos políticos y sociales que de ellos se derivan, será la fórmula utilizada para justificar la situación de privilegio de una minoría y la de exclusión sociopolítica para una inmensa mayoría. Los derechos del hombre, nucleados por el derecho de propiedad, van a ser interpretados desde el paradigma del individualismo posesivo y reconducidos a la hermenéutica de la tradiciones religiosa e histórica, como fuentes de legitimación.

Los doctrinarios fueron, desde una perspectiva cognitiva, quienes, frente a los revolucionarios y a los reaccionarios, que se movían guiados por el «doble frenesí» de la normatividad dogmática, cambiaron de percepciones y de hábitos a la hora de interpretar su contexto y de actuar en él y apostaron por un eclecticismo que les permitía «brujulear» y evolucionar según lo fueron haciendo las exigencias de la burguesía hegemónica. Al servicio de ésta instrumentalizaron pusieron todos los resortes materiales y espirituales y crearon una nueva forma de entender el principio de legitimidad histórica (declarando obsoleto el de la legitimidad dinástica $)^{7}$, que según ellos, declaraba a la burguesía como la clase providencialmente destinada a guiar los destinos de la sociedad.

El liberalismo doctrinario lleva a su perfección lo que Macpherson llamó «la hazaña» de Locke y la de todo el liberalismo conservador posterior que consistirá

6 Lu influencia en España de este grupo de políticos e intelectuales franceses, que durante la Restauración y hasta la revolución democrática del 48 buscaron legitimar la hegemonía de la burguesía, trazando una vía media entre el tradicionalismo legitimista y el liberalismo revolucionario, fue enorme. Desde el Estatuto Real de 1834 hasta la Restaturación canovista, el siglo XIX español estará decisivamente marcado por las directrices de los doctrinarios. Figuras como Donoso Cortés, Alcalá Galiano y, más tarde Cánovas, figuran en la nómina de los doctrinarios. Véase la obra clásica ya citada sobre el tema: Díez del Corral, El liberalismo doctrinario. C.E.C. Madrid. 1984. Para una introducción más breve al tema, véase el capítulo que dedica J.L. Abellán al tema en su obra Historia crítica del Pensamiento español. vol. IV.

7 Es sorprendente ver cómo los doctrinarios legitiman la sustitución de Carlos X por Luis Felipe de Orleans en nombre de la razón histórica, olvidando el tradicional principio de la legitimidad dinástica. 
en aceptar como moral la desigualdad entre pobres y ricos, considerándola natural. En la economía divina estaría inscrito este proyecto providencial de que quien se enriquece sin límites legales o morales es quien cumple con una vocación humanizadora, ya que sólo así alcanza el hombre su plenitud humana y social ${ }^{8}$.

Su materialismo histórico reaccionario se supo revestir de una filosofía de la historia, en la que la trascendencia religiosa, el discurso ético-religioso y la vuelta a unas prácticas «creyentes», sirvieron para legitimar un sistema socioeconómico y político construido según la lógica del individualismo posesivo. Los burgueses enriquecidos necesitaban un plus de legitimación de su materialismo práctico y lo encontraron en la ética y en la religión. Así, el «enriquecerse a toda costa» pudo ser una vocación de cristianos «honorables». Aunque este desodorante no pudo sustituir el olor a podrido que los «materialistas históricos progresistas» denunciaban en tal «idealismo», sirvió para maquillar el «humanismo de las compatibilidades» ${ }^{9}$, que haría fortuna entre muchas gentes de «buena conciencia». Este «humanismo» consistía en invocar los principios ilustrados de los derechos y libertades, pero vaciándolos de su vocación universalista e igualitaria. Durante bastante tiempo, la parábola del «hombre rico» tendría un final feliz. Por fin era compatible lo que el evangelio presentaba como imposible: que un camello entrara por el ojo de una aguja y estuviera cargado de oro.

8 Locke fue un defensor del iusnaturalismo racionalista moderno y, desde éste, de los derechos naturales a la libertad y a la igualdad de todos los seres humanos, ya que el Creador quiso que todos los hombres tuvieran acceso a los bienes que necesitan para ser libres e iguales, pero, a la vez, justificó el derecho de propiedad privada burgués como un derecho natural y universal. Locke no se conformó con argumentar como lo habría hecho un mercantilista al uso, sino que, como dice Macpherson, hizo algo de mucha más trascendencia. La hazaña de Locke está en que da una base moral a la apropiación burguesa. La concepción tradicional, según la cual, la propiedad y el trabajo eran funciones sociales y la propiedad implicaba obligaciones sociales, se ve por ello minada. Pero no sólo acaba con la descalificación moral que lastraba la apropiación capitalista ilimitada, sino que, además, justificó, como naturales, una diferencia de clases en derechos y en racionalidad, y al hacerlo proporcionó una base moral positiva a la sociedad capitalista. La trascendencia de este tema para comprender el alcance desigualitario y excluyente del propietarismo burgués exige, como lo hace Macpherson, explicar cómo legitima Locke la desigualdad de clases, el sufragio censitario y el consecuente ejercicio autoritario del poder, cuando sea preciso. Tener, saber y poder, aparecen ya como la trinidad sagrada que regirá el orden burgués.

9 La crítica de los socialistas, especialmente de los socialistas libertarios o anarquistas, a este materialismo reaccionario es poco conocida, pero creo que es de una enorme lucidez. Véase Velasco, D., Ética y poder político en la obra de M. Bakunin. Universidad de Deusto, 1993, 99-164; Véase, asimismo, la crítica que E. Tierno Galván hizo del «humanismo de las compatibilidades» en "Humanismo y sociedad». Así hay que entender el humanismo que sirve igual para los pobres que para los ricos, como servía el contrato social burgués denunciado por Rousseau. Un humanismo y un contrato tan mendaces como inmorales. (Ver Boletín Informativo del Seminario de Derecho Político, núms. 29-30. Salamanca, 1963. Un buen resumen de este texto es el que hace Díaz, E., en Pensamiento español en la era de Franco, 1 939-1975. Tecnos. Madrid, 1983, 126-129) 
En su «espiritualismo ecléctico de amplia base» que, como recuerda Díez del Corral, alguien bautizó como «vinagreta filosófica», los doctrinarios echarán mano de todos los argumentos que sirvan para justificar un liberalismo elitista, censitario y excluyente. Para instaurar la «soberanía de la inteligencia» y el «gobierno de los mejores» que, desde el horizonte de la legitimidad histórica, son «las clases medias», ya que en ellas reside la fuerza moral y material, es preciso vaciar la interpretación de los derechos del hombre de su expresión «populista», es decir, participativa e igualitaria. Como dice Díez del Corral, era «preciso efectuar una selección destacando a los mejores y más influyentes, es decir, a aquéllos que dispongan de los medios conducentes al mayor perfeccionamiento propio y la más eficaz ayuda de los demás. Estos medios son evidentemente la más alta capacidad para dirigir la vida de relación entre los hombres, la inteligencia y la instrucción. Pero para adquirir tales condiciones es imprescindible la propiedad; sin ella no es posible alcanzar un elevado desarrollo espiritual, ni influjo material... Desaparecidas las viejas diferencias estamentales, surge otra clasista, ya no determinada por el complejo vital, que constituye el tipo de noble o clérigo, sino por un hecho fundamentalmente económico: la propiedad. La traducción política formal de esta diferencia social es el sufragio censitario y, con él, una simbólica «representación virtual» que acaba vaciando de contenido el proceso democrático.

Inteligencia, riqueza y poder, serán, para el liberalismo doctrinario, la sacrosanta trinidad, que un providencialismo más o menos explícitamente religioso ha reservado para la burguesía. Sólo ésta, gracias a su propiedad, puede gozar de los derechos de la cultura y dedicarse al ejercicio del poder. Autores españoles, como Donoso o Cánovas, serán quienes de forma más explícitamente religiosa reflejen la legitimación providencialista de esta trinidad sacrosanta, que convierte, de hecho, a los burgueses en los titulares exclusivos de los derechos políticos y, por ello, de buena parte de los derechos del hombre.

En la posición de los doctrinarios se da un fenómeno que ha ido acentuándose hasta nuestros días y que vicia de raíz la calidad humana de su proyecto. $\mathrm{Me}$ refiero a una actitud de amnesia histórica y sociológica. No sólo olvidaron que la revolución liberal tenía una vocación universal, de carácter emancipador, por la que todos estaban llamados a poder ser beneficiarios del cumplimiento de sus promesas, sino que, además, lograron borrar de su mundo la memoria passionis de las víctimas y excluidos, los perdedores netos de la Revolución, los pobres, gracias a cuyo sacrificio ellos podían gozar de su situación de privilegio. Su forma de ver la sociedad era tan etnocentrista y excluyente que a los grupos sociales excluidos de la ciudadanía les consideraba un problema técnico y moral que había que plantear y resolver en función de los intereses del «orden burgués». Tras vaciar la cuestión de toda dimensión política, lo que evitaba el tener que reflexionar sobre las causas estructurales de la exclusión social, se busca moralizar a los excluidos en los valores del orden y de la disciplina (sobre todo a través del trabajo), para integrarlos así en el sistema. La estrategia de asimilación responde a la convicción central del humanismo de la compatibilidad: la moral del rico y la del pobre son la misma, sólo que el pobre, discapacitado, necesita más 
disciplina y más educación, para asimilar sus valores. Pero el problema de la pobreza no está en las estructuras desigualitarias e injustas del orden burgués, sino en la fábrica moral de los individuos que hay que saber poner a punto. Como dirá E. Dussel, esta amnesia se hará consustancial a todo liberalismo, al desconocer éste las estructuras históricas de la desigualdad ${ }^{10}$.

El contexto de la recuperación de Tocqueville, debido, sobre todo, al fracaso de las utopías revolucionarias y a la trágica experiencia de los totalitarismos europeos, que obligaron a valorar miradas tan lúcidas y originales como la suya respecto a la tiranía de las mayorías y al despotismo del poder, ha sido objeto de numerosos análisis que no vamos a exponer ahora ${ }^{11}$. Me parece más relevante subrayar que, en un contexto de crisis tan radical de nuestras democracias y de progresivo afianzamiento de lo que he llamado «fascismo social» ${ }^{12}$, se comprende fácilmente la importancia de estudiar a un autor como Tocqueville.

\section{LA SUPERVIVENCIA IDEOLÓGICA DEL LIBERALISMO DOCTRINARIO Y LA CRÍTICA DE A. DE TOCQUEVILLE}

Aunque soy consciente de que mi planteamiento puede parecer un anacronismo injustificado, lo hago partiendo de la convicción de que el proceso de la convencionalmente llamada globalización, construida desde la hegemonía

10 Dussel, E. Ética de la Liberación. Madrid. Trotta, 1998, 174 ss.

11 Es conocida la posición de R. Aron, para quien, siendo Tocqueville una de las figuras más relevantes en los orígenes del pensamiento sociológico, no suele ser reconocido como tal. «Tocqueville no figura de ordinario entre los inspiradores del pensamiento sociológico. Esta falta de reconocimiento de una obra importante me parece injusta ». ARON, R., Les étapes de la pensée sociologique. Paris. Gallimard, 1967, 223. El mismo Aron reconocerá que al «no leerse a Tocqueville ni en la École Normale, ni en la sección filosófica de la Sorbona, comenzó a estudiar a Tocqueville en 1950, ocupando ya la cátedra de Sociología». (ARON, R., «Tocqueville retrouvé», en The Tocqueville revue/La Revue Tocqueville, vol. 1, n. 1-automne 1979, 8-23), citado según la reproducción del artículo en el número monográfico de la misma revista que recoge los mejores artículos de los 25 últimos años: Tocqueville et l'esprit de la démocratie. The Tocqueville Review/La Revue Tocqueville. Sciences PO Paris Les Presses, 2005. Me parece significativo el caso de SHELdon Wolin, que apenas cita a Tocqueville en su obra (véase Política $y$ perspectiva. Continuidad y cambio en el pensamiento político occidental Buenos Aires. Amorrortu, 1973, y que, en una reciente y voluminosa obra dedicada a Tocqueville, parece querer resarcirse de su error, aunque, como comenta M. Richter, Wolin sólo busca criticar a Tocqueville por conservador e incoherente. Véase «The deposition of Alexis de Tocqueville?, en The Tocqueville Review, vol. XXIII, n. 2 (2002), 173-199, en donde Richter comenta la obra de Wolin, Tocqueville Between Two Worlds. The Making of Political and Theoretical Life, Princenton Univ. Press, 2001. F., Mélonio, en su obra Tocqueville et les Français. Aubier Paris 1993, en el apartado dedicado al «retorno de Tocqueville» (pp. 271-293), da una explicación plausible del «enigma» de su reciente reconocimiento y, refiriéndose al caso de Francia, dice que dicho reconocimiento data de la posguerra y es posterior al redescubrimiento de su obra en los países aplastados por el totalitarismo (obras de Croce, Mayer, etc.).

12 Velasco, D., Fascismo social: políticas del miedo y servidumbre voluntaria. ¿Qué hacer?, Universidad de Deusto, 2013. 
«neoliberal», es una etapa singular del capitalismo liberal, que, además de cuestionar de raíz los ideales revolucionarios de libertad e igualdad, busca imponer su proyecto de dominación de la sociedad como fascismo social. Es obvio que la actual fase de dicho capitalismo tiene muchos aspectos que la diferencian no sólo del capitalismo decimonónico que conoció Tocqueville, y que ni siquiera es fácil hacer una valoración adecuada del mismo, como a menudo lo hacemos, comparándolo con la versión fordista-keynesiana que hasta no hace pocas décadas nos servía de referente de un "capitalismo razonable». Relevantes analistas hablan de una nueva etapa en la que ya no será posible reeditar pactos como el de la posguerra ni hacer viable un Estado de bienestar aunque sea deteriorado como el actual. Sin embargo, no creo que sea exagerado decir que, en no pocos aspectos, nuestras sociedades están sufriendo un proceso de regresión democrática que nos sitúa en pleno «liberalismo doctrinario». Creo que, hoy, cobra actualidad el tema del "pauperismo», como la tiene cada vez mayor el lema del «enrichissez-vouz» a toda costa. La escandalosa y creciente desigualdad, causa y efecto a la vez, de la pobreza, de la injusticia y de la perversión de la democracia, se ha convertido en la expresión más plástica y evidente de la «hegemonía de la razón cínica». Stiglitz y Piketty nos han mostrado recientemente con sólida argumentación y evidencias empíricas, que el abandono del ideal de la igualdad y el crecimiento de la desigualdad está siendo una grave amenaza para las sociedades democráticas. P. Rosanvallon, en un magnífico libro, tras lamentar el olvido real en nuestros días del ideal revolucionario de la igualdad y de las plasmaciones prácticas de éste en el siglo $\mathrm{xx}$, se refiere a algunas perversiones democráticas que se dieron en el siglo XIx y que se están acentuando en nuestros días, evidenciando una regresión histórica al respecto ${ }^{13}$. Buena parte de estas perversiones decimonónicas se dan en el

13 Rosanvallon, P., La sociedad de los iguales. Barcelona. RBA Libros, 2012. Entre otras, cita la perversión liberal conservadora (reducción al mínimo de la igualdad, estigmatización del obrero, criminalización de la pobreza y sus remedios represivos, legitimaciones seudocientíficas de la desigualdad y su naturalización); el nacional-proteccionismo (entendido más como filosofía social que como política económica: «la patria organizada» de la III República francesa y su deriva colonialista, como sustitución del ideal democrático por el de la igualdad negativa, el de la pertenencia a una misma comunidad de rechazo y de distanciamiento); el racismo constituyente (que tiene en la segregación una nueva economía de la distancia y de la desigualdad). Parece, pues, pertinente afirmar que en muchos aspectos la gestión antidemocrática de la crisis nos está retrotayendo al siglo xIx. Ya que el siglo xx, como sigue diciendo Rosanvallon, ha sido el que, en buena medida, ha pasado página a estas perversiones y ha creado los Estados Providencia y, de la mano de la redistribución y del sufragio universal, ha luchado contra la desigualdad. Este movimiento se hará a través de tres grandes reformas: la institución del impuesto progresivo (impuesto-solidaridad o impuesto-redistribución) que busca nivelar algo la situación y lucha contra la pobreza y la marginación. La sociedad aseguradora rompe con la filosofía decimonónica del pauperismo y deja de estigmatizar a los pobres. Se instaura un nuevo Estado social que se hace cargo de seguros, pensiones, etc., superando el asistencialismo caritativo anterior. Asimismo, la regulación colectiva del trabajo, mediante la legalización de los sindicatos, supuso una ruptura con la visión liberal del contrato. 
actual contexto. Así lo evidencian un sin fin de medidas tomadas por el brutal plan de ajuste, conocido como "austericidio», que han afectado a todos los ámbitos de la vida sociopolítica, desde cambiar las constituciones para fragilizar las garantías de los derechos fundamentales, hasta imposibilitar las diferentes plasmaciones de dichos derechos en ámbitos como el laboral, sanitario, educativo, y poner en riesgo la satisfacción de derechos básicos, entre ellos el derecho a la subsistencia.

Obviamente, no se trata de una simple vuelta atrás. Ha habido factores históricos que han contribuido claramente a este cambio (caída del comunismo y descenso del reformismo del miedo, el olvido de los grandes sufrimientos colectivos) así como importantes causas estructurales (la crisis mecánica y moral de las instituciones de solidaridad, el advenimiento de un nuevo capitalismo, metamorfosis del individualismo) que amenazan al núcleo mismo de la fábrica de las sociedades democráticas. Es fundamental repensar estas causas estructurales, para saber a qué nos enfrentamos y qué podemos hacer ${ }^{14}$.

Tocqueville, desde su contexto decimonónico, nos permite recrear algunas de sus aportaciones más valiosas para la construcción de sociedades más igualitarias y libres, a la vez.

\section{La Vigencia actual del «Liberalismo nUeVo» De TocQueVille como ReFerente CRÍTICO DE IMPORTANTES ASPECTOS DE ACTUAL NEOLIBERALISMO}

El liberalismo tocquevilliano tiene tres dimensiones que nunca antes de Tocqueville se habían conjugado en el pensamiento liberal: la económica, la social y la moral. La libertad tiene tres dimensiones constitutivas e interdependientes: la dimensión económica (el mercado libre, pero dejando lugar a la interferencia política con intervenciones específicas como un sistema de tasas que debe ser favorable al pobre. En términos actuales podríamos afirmar

14 Rosanvallon muestra cómo la crisis de las instituciones de solidaridad, sobre todo del Estado de Bienestar (EB), que se inicia en las últimas décadas del siglo xx, se ha acentuado con la creciente imposición del modelo de Estado asistencial para las situaciones de exclusión más sangrantes, pero con una visión decimonónica de la pobreza y de los pobres (la exclusión se vincula a los comportamientos y decisiones individuales). La justicia se disocia cada vez más de la solidaridad y los grupos de mayor riesgo serán los más penalizados. Las instituciones y políticas de seguridad creadas en 1945 (que tuvieron más un carácter pragmático que una buena fundamentación teórica de la igualdad) han ido dando paso a una sorda deslegitimación del Estado providencia, comenzando por la cuestión fiscal (Reagan, Thatcher). Se debilita el sentimiento de que hay una deuda social que saldar y se desplaza la sensibilidad a lo ecológico y a las generaciones futuras más que a los pobres actuales. También decrece el sentimiento social de solidaridad por un proceso de desobjetivación del infortunio. La pobreza más que injusticia social vuelve a ser responsabilidad de los pobres. Este cambio mental y cultural es clave para hacer plausibles los cambios todavía peores que van a venir frente al todavía resistente Estado-social-redistribuidor, al que se sigue calificando de depredador y cleptocrático.. 
que Tocqueville dice sí a una economía de mercado y no a una sociedad de mercado.). La dimensión social de la libertad que contempla tanto su aspecto individual y privado como un aspecto público, que incluye tanto la libertad de interferencia como la participación en las comunidades (cuestionando la posición de Constant). Como para Aristóteles, el hombre tocquevilliano es un animal político, pero, a diferencia de él, el animal democrático de Tocqueville tiene otras dimensiones tan importantes o más que la política, como la asociativa, la religiosa o la dimensión moral de la libertad que implica una responsabilidad que está más allá del autointerés ilustrado.

Creo que una de las aportaciones con mayor vigencia de la obra de Tocqueville es la crítica que hace al materialismo economicista y propietarista que ve encarnado en su época y, en especial, en el liberalismo doctrinario. En el Prefacio de El Antiguo Régimen y la Revolución, Tocqueville recuerda lo que, veinte años antes, ha desarrollado profusamente en la Democracia en América. Se refiere el autor a tres verdades muy claras: la inevitable destrucción de la aristocracia; la enorme dificultad de evitar gobiernos absolutos en sociedades sin aristocracias y, finalmente, que el despotismo producirá en dichas sociedades los efectos más perniciosos desarrollando en ellas los peores vicios. «En ellas, al no estar los hombres ligados entre sí por ningún lazo de casta, de clase, de corporación ni de familia, se sienten demasiado inclinados a no preocuparse más que de sus intereses particulares, demasiado propensos a no mirar más que por sí mismos y a replegarse en un individualismo estrecho en el que toda virtud política está sofocada... El afán de enriquecerse, a toda costa, la manía de los negocios, el amor al lucro, la búsqueda del bienestar y de los goces materiales son en ellas las pasiones más comunes» ${ }^{15}$.

Este «materialismo histórico reaccionario» es letal para la causa de la libertad y, en definitiva, de la democracia. El «liberalismo nuevo» de Tocqueville proclama que «sólo la libertad puede combatir eficazmente en esta clase de sociedades los vicios que les son naturales y detenerlas en la pendiente por la que se deslizan. En efecto sólo ella puede sacar a los ciudadanos del aislamiento en que la misma independencia de su condición los hace vivir... Sólo ella es capaz de arrancarlos del culto al dinero y del tráfago cotidiano de sus negocios particulares, para hacerles percibir y sentir en todo momento que la patria está por encima y en torno a todos ellos; solamente ella sustituye de vez en cuando el amor al bienestar, por pasiones más fuertes y más elevadas, sólo

15 Tocoueville, A. DE, El Antiguo Régimen y la Revolución. Madrid. Guadarrama, 1969, 19-21; «Encuentro entre los materialistas muchas cosas que me ofenden. Sus doctrinas me parecen perniciosas y su orgullo me indigna: si su sistema pudiera servir de alguna utilidad al hombre, me parece que sería solamente la de darles una modesta idea de sí mismos; pero ellos no dejan ver que así sea, y cuando cree haber probado suficientemente que son brutos, se muestran tan soberbios como si hubiesen demostrado que son dioses. El materialismo es, en todas las naciones, una enfermedad peligrosa del espíritu humano, pero debe temerse particularmente en un pueblo democrático, porque se combina maravillosamente con el vicio más familiar del corazón de estos pueblos». DA, TII, $2^{\text {a }}$ parte, 502. 
ella proporciona a la ambición objetivos más grandiosos que la adquisición de riquezas, y crea la luz que permite ver y juzgar los vicios y las virtudes de los hombres» ${ }^{16}$.

La forma de hacerlo es tener en cuenta la complejidad de lo social (ámbitos interdependientes de la realidad y plurirregionalidad de lo sociopolítico) buscando el equilibrio entre los extremos representados por el liberalismo industrialista, de carácter economicista, que se olvida de la dimensión social y moral de la libertad, y por el socialismo estatista que acaba negando la libertad misma. El camino es lograr que en las sociedades emerjan «las nuevas aristocracias democráticas», que Tocqueville ve plasmadas en el hecho asociaciativo, tal como se da en Norteamérica. Las asociaciones, dice Tocqueville saliendo al paso de la política represiva y antiasociacionista de los doctrinarios franceses, no sólo no son enemigas de la libertad individual positiva, sino que son su condición de posibilidad en la modernidad democrática. Ph. Chanial ${ }^{17}$ ha mostrado cómo en la obra de Tocqueville conviven tres aproximaciones sociológicas diferentes al hecho asociativo. Una primera, que llama «republicanocívica, que prima el punto de vista de la virtud; una segunda, que denomina «república utilitarista» y que prima el punto de vista del interés; finalmente, una tercera, que llama «aristodemocrática», que desvela la verdadera naturaleza del liberalismo tocquevilliano, que es democrático y aristocrático a la vez.

Las tres perspectivas se desarrollan a un mismo tiempo, con sus lógicas contradictorias, y sólo una visión de conjunto nos permite hacernos una idea cabal de la originalidad de la obra tocquevilliana. Si su preocupación casi obsesiva es impedir la deriva despótica del poder democrático y atajar de raíz las causas que la provocan y retroalimentan, hasta convertir la pasión igualitaria en gusto depravado por la servidumbre, su tarea ineludible consistirá en hacer ver por qué las asociaciones no sólo no son enemigas de la libertad, como un liberalismo individualista radical de larga tradición ha hecho creer, en consonancia con su visión negativa de la libertad como independencia y no coerción, sino que, por al contrario, son la condición de posibilidad de la libertad positiva, en la modernidad democrática ${ }^{18}$. En la tradicional querella sobre la libertad de los antiguos y los modernos, Tocqueville se posiciona como defensor de la síntesis de ambas. La posición moderada de Tocqueville se refleja en la forma en que valora la doctrina americana del «interés bien entendido» ${ }^{19}$. Él cree que

16 Ibid, 21-22

17 Chanial, P., "Honneur, vertu et intérêt. Les sociologies de l'association d'Alexis de Tocqueville» en Cahiers internationales de Sociologie Vol. CXVII, jul-dec, 2004, 197-223.

18 Tocqueville, en «Lettre intérieure sur la situation intérieure de la France», 1843, ataca la política represiva de Guizot y de los doctrinarios, simbolizada en la ley del 10 de abril de 1834 que era muy restrictiva del derecho de asociación. La situación, una década después se agravó aún más. (ver CHANIAL, op. cit., 208, nota n. 2).

19 «Casi nunca se dice en Estados Unidos que la virtud es bella; se sostiene que es útil y esto mismo se prueba todos los días... La doctrina del interés bien entendido no es nueva; pero en los norteamericanos de nuestros días ha sido universalmente admitida y se ha hecho popular; se la encuentra en el fondo de todas las acciones y brota a través de todos los 
es posible garantizar un nivel razonable de virtud sin tener que sacrificar el interés individual, al que considera la seña sociológica más relevante para el futuro de la humanidad ${ }^{20}$.

Tocqueville centra su atención en dos principales enemigos que tiene la libertad (la democracia) en las sociedades industriales, como son la pobreza y el socialismo estatista. Tocqueville estuvo muy sensibilizado con el tema de la pobreza y tanto sus «memorias sobre el pauperismo» (la segunda no la concluyó), como, más tarde, su proyecto de partido político («La joven izquierda» (1847), que no cuajó, y el documento programático que escribió para él: «Fragmentos para una política social» (en el que desarrolla medidas para atajar la pobreza, como un sistema de tasas, etc.,), son un ejemplo de dicha preocupación. Tocqueville toma distancia respecto a las posiciones de representantes del industrialismo («economía política clásica»), del catolicismo social y del liberalismo doctrinario $^{21}$. Frente a los economistas liberales cuestiona la compatibilidad que estos propugnan entre individualismo posesivo y republicanismo y propone el «interés bien entendido», al que nos hemos referido. Frente al catolicismo social, propone medidas que superen el asistencialismo tanto privado como público. Tanto su análisis estructural de los problemas, que le lleva a subrayar la interdependencia entre el desarrollo económico y las causas sociales, políticas, religiosas, etc., como su defensa de la separación de la Iglesia y del Estado y de las instituciones liberales, le alejan de ellos. Frente a los doctrinarios, denuncia su propietarismo, desigualitarismo y tradicionalismo, como hemos visto.

Tocqueville manifiesta una clara hostilidad frente al socialismo, ya que para él el socialismo no es el desarrollo de la democracia sino su adversario. En la descripción que hace de la situación social de Francia, hace algunas propuestas

discursos. Por todas partes se halla, y lo mismo se encuentra en los labios del pobre que en los del rico. "(DA T II, $2^{\text {a }}$ parte, cap. VIII. pp. 484-485)

20 "Es menester, pues, esperar que el interés individual se haga más que nunca el principal móvil de los hombres, si no el único; pero nos resta saber de qué manera entenderá cada hombre su interés individual». (DA, T II, parte $2^{\mathrm{a}}$, cap. VIII, p 486); "Cuando el gusto de los goces materiales se desenvuelve en uno de estos pueblos con más rapidez que las luces y los hábitos de la libertad, sobreviene un momento en que los hombres son arrastrados como fuera de sí mismos , a la vista de estos nuevos bienes que van pronto a adquirir. Preocupados por el solo cuidado de hacer fortuna, no ven el lazo estrecho que une la particular de cada uno de ellos a la prosperidad de todos, y no hay necesidad de arrancar voluntariamente a tales ciudadanos los derechos que poseen; pues los dejan escapar voluntariamente ellos mismos. El ejercicio de sus deberes políticos les parece un contratiempo que los distrae de su industria; y, si se trata de elegir a sus representantes, de prestar auxilio a la autoridad o de discutir en común los negocios públicos, el tiempo les falta, porque no saben disiparlo en trabajos inútiles. Estos son allí juegos de ociosos, que no conciernen a hombres graves ocupados en los intereses serios de la vida. Tales personas creen seguir la doctrina del interés, pero no se forman de ella sino una falsa idea, y para atender mejor a lo que llaman "sus negocios" descuidan el principal, que es el ser simples dueños de sí mismos» (DA. T II, 2 ${ }^{\mathrm{a}}$ parte, cap. XIV, 498-499).

${ }_{21}$ WeLCH, CH. B., «Tocqueville's resistance to the social», History of European Ideas, 30, 2004, 83-107. 
muy significativas para comprender su posición. «La revolución francesa quiso que no hubiese clases, no tuvo jamás la idea de dividir a los ciudadanos, como ustedes hacen, en propietarios y proletarios. En ninguno de los principales documentos de la revolución francesa encontrarán esas palabras cargadas de odios y de guerras. La revolución quiso que, políticamente, no hubiese clases; la restauración de Julio, han querido lo contrario: Nosotros debemos desear lo que quisieron nuestros padres. La revolución francesa quiso que los cargos públicos fuesen iguales, realmente iguales para todos los ciudadanos, pero fracasó; los cargos públicos siguen siendo, en muchos aspectos desiguales; así, pues, debemos conseguir que sean iguales... La revolución francesa, ya lo he dicho, no tuvo la pretensión ridícula de crear un poder social que asegurase directamente por sí mismo la fortuna, el bienestar y la felicidad de cada individuo, que sustituye la prudencia práctica e interesada de los ciudadanos por la muy discutible del gobierno; creía que era bastante con dar a cada ciudadano luces y libertad... La revolución francesa, finalmente, deseó - y es ese deseo el que la hizo no sólo sagrada, sino santa a los ojos del pueblo- introducir la caridad en la política; reconoció que el estado tenía deberes para con los pobres, para con los ciudadanos que sufren, idea mucho más general, más amplia y más elevada que la que antes se tenía... Eso es lo que la revolución francesa quiso hacer; eso es lo que nosotros debemos lograr. ...Sí, la Revolución de Febrero debe ser cristiana y democrática, pero no debe ser socialista. Estas palabras resumen todo mi pensamiento ${ }^{22}$. Tocqueville no cuestiona las estructuras del sistema capitalista y ve compatible a este último con el republicanismo democrático y cristiano, a la vez. Se opone al socialismo de carácter revolucionario y su búsqueda de soluciones se pierde en fórmulas que adolecen de elitismo y paternalismo, sin llegar a sacar las consecuencias que se podrían derivar de sus propios análisis.

\section{4. ¿LA «IRRESISTIBLE IGUALACIÓN DE LAS CONDICIONES SOCIALES» O LA CRECIENTE DESIGUALDAD ESTRUCTURAL DEL CAPITALISMO?}

Para Tocqueville la igualación de condiciones sociales es una ley providencial que desde hace siglos se viene afirmando de forma irreversible. «El desarrollo gradual de condiciones es, pues, un hecho providencial, y tiene las siguientes características: es universal, durable, escapa a la potestad humana y todos los acontecimientos, como todos los hombres, sirven para su desarrollo. ¿Es sensato creer que un movimiento social que viene de tan lejos, puede ser detenido por los esfuerzos de una generación? ¿Puede pensarse que después de haber destruido el feudalismo y vencido a los reyes, la democracia retrocederá ante los burgueses y los ricos? ¿Se detendrá ahora que se ha vuelto tan fuerte

22 Tocoueville, «Sobre la cuestión del derecho al trabajo», en GiBert, P., Igualdad social y libertad política. Madrid. Magisterio español, 240-242. 
y sus adversarios tan débiles? ¿A dónde vamos? Nadie podría decirlo; los términos de comparación nos faltan; las condiciones son más iguales en nuestros días entre los cristianos, de lo que han sido nunca en ningún tiempo ni en ningún país del mundo; así, la grandeza de lo que ya está hecho impide prever lo que se puede hacer todavía ${ }^{23}$.

Hoy podemos preguntarnos qué habría pensado Tocqueville de haber conocido la enorme y creciente desigualdad que, a pesar de tanto tiempo transcurrido desde que escribió su obra, sigue abriendo una brecha injustificable desde todos los puntos de vista. ¿Lleva razón Tocqueville cuando apela a una ley histórica y social que, lejos de ser una ficción o una utopía necesarias, es un hecho social irreversible y universal.? Si nos fiamos de los análisis que científicos sociales tan solventes, como los ya citados Piketti o Stiglitz, hacen de nuestras sociedades, parece ser que Tocqueville se equivocó. La desigualdad ha aumentado de forma significativa a lo largo de los dos últimos siglos y parece que seguirá creciendo en el futuro, si no se toman medidas urgentes para atajar la acumulación del capital en manos de unas minorías privilegiadas. Parece como si Balzac que, en 1835, el mismo año en que Tocqueville escribió el primer volumen de La Democracia en América, escribía su novela El pobre Goriot, en la que quiere mostrar que la desigualdad por motivos de herencia pervive y predomina sobre la desigualdad generada con el ejercicio del trabajo profesional, siguiera cargado de razón. Hasta ahora, el ideal tocquevilliano de la igualdad ha seguido vigente en el imaginario de nuestras sociedades que, más allá de la evidencia empírica de la creciente desigualdad, se siguen reclamando democráticas. Pero, ante la deconstrucción creciente de este imaginario bajo la hegemonía del pensamiento neoliberal, cabe preguntarse si sigue teniendo vigencia el alcance epistemológico y antropopolítico del principio igualitario tal como lo entendía Tocqueville. El triunfante neoliberalismo no solo ha acabado con el modelo keynesiano-fordista de regulación del capitalismo, sino que ha impuesto una explotación y reproletarización de la fuerza de trabajo, que se traducen como precarización social en la que únicamente puede sentirse razonablemente seguro quien disfruta de las suficientes rentas del capital.

Recordemos que, para Tocqueville, la originalidad de las sociedades democráticas frente a las aristocráticas está en que, aunque en aquellas subsistan la pobreza y la desigualdad, estas están deslegitimadas desde el principio igualitario. En el horizonte de la conciencia social democrática, la igualdad y las posiciones extremas de arriba y abajo, de riqueza y pobreza, sólo son «accidentes». Cuando Tocqueville opone la «igualdad imaginaria» a la «desigualdad real», no sugiere que esta igualdad sea ficticia o ilusoria, sino todo lo contrario. Es el imaginario de la opinión pública el que es el principio generador de las sociedades democráticas. Aunque Tocqueville no dice que este imaginario acabará trayendo la igualdad real, todo su análisis sugiere que debería ser así y que los

23 DA Introducción, 33 
hombres democráticos no descansarán en la persecución de este objetivo, aunque no lo alcancen nunca ${ }^{24}$.

«En las democracias, no solamente son iguales los criados entre sí, sino que en cierto modo son iguales a sus señores. Esto necesita explicarse para que se comprenda bien. El sirviente a cada instante puede volverse amo, y espera a serlo en efecto; el sirviente no es otro hombre distinto del señor. ¿Quién, pues, ha dado al primero el derecho de mandar y ha forzado al segundo a obedecer? El convenio libre y momentáneo de las dos voluntades, pues no siendo naturalmente inferior el uno al otro, sólo viene a estarlo por cierto tiempo en virtud del contrato; y si por él es uno sirviente y señor el otro, en lo exterior son dos ciudadanos, dos hombres... Tal estado bajo la democracia no tiene nada de degradante, pues es elegido libremente, y adoptado sólo por algún tiempo; no crea ninguna desigualdad entre amo y el criado, ni la opinión pública lo deshonra ${ }^{25}$. Pero, subraya asimismo, que, mientras que la condición del amo y del esclavo se acercan, sus personas se alejan, al perder la fijeza, inmutabilidad y naturalidad que permiten la cristalización de los sentimientos. «El principal efecto de la democracia es convertir al amo y al servidor en extraños, poniéndoles uno al lado del otro, en vez de uno sobre el otro... En democracia los hombres no son ni iguales de hecho, ni "solamente" de derecho. Entre el

24 C. LÉFORT, en un breve y magnífico artículo, sobre la amenaza que supone la opinión pública democrática sobre el pensamiento, subraya los dos polos de esta visión tocquevilliana trágica del proceso democrático. Tras afirmar que estamos ante un razonamiento que no es vicioso, ya que la igualdad de condiciones es el rasgo característico del estado social, irresistible e irreversible, por lo que sería irracional condenarlo, dice así: «La primera razón que lo prohíbe es que la desigualdad de condiciones en otro tiempo considerada natural se revela ahora como contraria a la naturaleza. Sin embargo, el bien y el mal se tocan, porque la igualdad de condiciones hace nacer el sentimiento de que no hay un punto de diferencia justificable entre los hombres y, por tanto, el deseo de la igualdad real. Ahora bien, proyectada en lo real, la igualdad aparece como imaginaria. Sin duda, Tocqueville evoca un momento en su Introducción el camino hacia un estado social completamente igualitario: “¿Sería sabio creer que un movimiento social que viene de tan lejos podría ser suspendido por los esfuerzos de una generación? ¿Puede pensarse que, después de haber destruido el feudalismo y vencido a los reyes, la democracia reculará ante los burgueses y los ricos?". Pero la fórmula no parece estar construida más que para aterrorizar (el término está adelantado algunas líneas antes para calificar el sentimiento religioso que le inspira el movimiento social) a quienes, ignorando los retos del presente, no sueñan con acomodarse a las exigencias de la democracia. Por otro lado, su pensamiento se entrega cuando cuestiona que pueda borrarse jamás la distancia que separa al pueblo de la elite, o cuando declara que : "las instituciones democráticas despiertan y halagan la pasión de la igualdad sin poder jamás satisfacerla enteramente. Esta igualdad completa se escapa todos los días de las manos del pueblo en el mismo momento en que cree retenerla, y huye, como dice Pascal, con una huída eterna» (DA, T I, $2^{a}$ parte, cap. V. :214-215). LÉFORT, C., «La menace qui pèse sur la Pensée», en The Tocqueville Review/La Révue Tocqueville. Vol. XVIII, 1997. 1, 29-35 ; reproducción en el número de 2005, 298-299.

25 DA T.II, parte $3^{\text {a }}$, cap. 5, 533. La forma en que Tocqueville formula este radical cambio que el espíritu democrático introduce en las relaciones humanas y que tantas virtualidades sociogenéticas conlleva, como lo han mostrado los republicanistas al desarrollar el concepto de libertad como no dominación, me recuerda la otra figura paradigmática de la fenomenología del espíritu hegeliana que se ha hecho imprescindible en el pensamiento moderno. 
derecho y el hecho, se encuentre algo inasible, "imaginario", pero irresistible, que Tocqueville llama opinión pública, y que pone a los hombres aparentemente más desiguales en un elemento de igualdad y semejanza. La igualdad es el sensorium commune de la vida social democrática» ${ }^{26}$.

Para Tocqueville, no basta, pues, con que las sociedades democráticas regulen sus relaciones con leyes igualitarias, sino que deberían asumir con todas las consecuencias el principio de la igualdad universal, empezando por compartir un imaginario democrático capaz de priorizar el principio de igualdad universal de todos los seres humanos sobre los particularismos desigualitarios y excluyentes de la raza, la clase o la religión, por ejemplo. Tocqueville plantea, con claridad, el problema, cuando analiza la cuestión etnorracial en la democracia americana. La forma en que los angloamericanos se relacionan con los indios nativos y con los negros es la expresión de una autocomprensión de la sociedad democrática, típica de los euroamericanos, que está lastrada por el prejuicio desigualitario y excluyente. El interés de la obra de Tocqueville está en que nos muestra con gran lucidez cuál ha sido la estrategia racializadora de las relaciones que los angloamericanos establecen con «los otros», indios y negros, y que desemboca en la liquidación progresiva de los primeros y en la esclavización de los segundos ${ }^{13}$.. Esta forma de abordar la cuestión del "otro», del extranjero, tiene una enorme actualidad en nuestros días ${ }^{14}$. Los prejuicios que se instalan en la mentalidad de una sociedad son más consistentes que las leyes. Por eso, para Tocqueville, una de las causas que hay que analizar es la tiranía de una opinión pública que hace que el color de la piel se instrumentalice para perpetuar los prejuicios, de tal forma que cuando el color de la piel se diluya se racializará cualquier vestigio imaginado del mismo, o cualquier otro rasgo del individuo humano que pueda servir de análogo funcional para el prejuicio racista.

Tocqueville presenta un imaginario igualitario en el que cabe la desigualdad real, pero como algo que carece de legitimidad social democrática. Creo que es importante subrayar esta gran aportación de Tocqueville, ya que hace plausible mantener la vigencia del ideal igualitario más allá de las evidencias empíricas que lo niegan. Es sabido que para poder vivir juntos necesitamos echar mano de legitimaciones ideológicas que los mismos clásicos que las formulan califican de ficciones necesarias. Así, la razón universal y la voluntad general son construcciones de la realidad que, contra toda evidencia empírica, se han hecho necesarias como lo es una utopía razonable para toda sociedad humana. Todavía hoy seguimos viviendo de esas ficciones verdaderas que, contra la evidencia empírica, son constitutivas de nuestras democracias: la igualdad, la soberanía popular, la representatividad del delegado, la accesibilidad de toda la ciudadanía a los cargos, la inclusión ilimitada ${ }^{27}$.

Esta forma de entender el ideal igualitario va acompañada en la obra de Tocqueville de una nueva manera de enfocar la historia (continuidad-ruptura,

26 Manent, P., Tocqueville el la nature de la démocratie, Julliard, Paris (1982),p. 55.

27 Simone, R., «Cómo fracasan las democracias». Claves de Razón Práctica. (2014) n. 236. 
singular-universal, etc.), en la que tiene pleno sentido su lúcida afirmación de que «la historia muere perpetuándose». Hay una metáfora bíblica que utiliza Tocqueville para referirse a contextos históricos como el que él vivió y como el que nos toca vivir a nosotros, que refleja bien lo que decimos. Es la metáfora del «diluvio universal». Pensar la realidad actual desde la metáfora del «diluvio neoliberal» y ver lo que tiene de catástrofe (barrido de los derechos sociales y auge del fascismo social) y lo que tiene de oportunidad (surgimiento de nuevos movimientos sociales y políticos).

Tocqueville nos advierte de que la pasión igualitaria y la indignación que provoca la omnipresente y escandalosa desigualdad pueden acarrearnos consecuencias indeseadas e incluso funestas para la causa de la libertad. «Hay en efecto una pasión viril y legítima por la igualdad, que excita a los hombres a querer ser todos fuertes y estimados. Esa pasión tiende a elevar a los pequeños al rango de los grandes; pero se encuentra también en el corazón humano un gusto depravado por la igualdad, que inclina a los débiles a querer atraer a los fuertes a su nivel, y que conduce a los hombres a preferir la igualdad en la servidumbre a la igualdad en la libertad. No es que los pueblos cuyo estado social es democrático desprecien naturalmente la libertad. Tienen por el contrario un gusto instintivo por ella. Pero la libertad no es el objeto principal y continuo de su deseo; lo que aman con amor eterno es la igualdad; se lanzan hacia ella por impulsión rápida y por esfuerzos súbitos, y si no logran el fin se resignan; pero nada podría satisfacerles sin la igualdad, y desearían más perecer que perderla ${ }^{28}$. Ante el vértigo que da ver que la libertad democrática puede ejercerse liquidando los lazos sociales de las sociedades aristocráticas y confiando el destino de los individuos y sociedades a la instauración de una soberanía democrática carente de límites, proclive al despotismo y a la tiranía, y caldo de cultivo de la servidumbre voluntaria, Tocqueville busca fórmulas que sigan garantizando la libertad. Más allá de las ambigüedades e incluso contradicciones que pueda presentar su posición ante el problema de la soberanía y sus límites, creo que esta sigue siendo una de sus grandes aportaciones cuya actual vigencia nos obliga a seguir pensando en ella, sobre todo, en estos momentos en los que el fascismo social es más que una mera amenaza ${ }^{29}$. Aceptar, como hace Tocqueville, una ley general de la justicia que trascienda cualquier voluntad soberana o aceptar, como hacen algunos autores en nuestros días, un «coto vedado» que el poder soberano no puede invadir, es responder a la necesidad tocquevillina de encontrar la fórmula para evitar el despotismo y la tiranía del

28 DA, T.I. $1^{\text {a }}$ parte, cap. III, 72-73; Para abundar en esta convicción de Tocqueville, recomiendo al lector la lectura del cap. I de la parte $1^{\text {a }}$ del tomo II, titulado «Por qué razón los pueblos democráticos muestran un amor más vehemente y más durable hacia la igualdad que a favor de la libertad», que algún autor ha considerado, junto con la Introducción, lo más importante de la DA

29 "Yo miro como impía y detestable esta máxima de que la soberanía del pueblo tiene derecho hacer todo y, sin embargo, sitúo en las voluntades de la mayoría el origen de todos los poderes. ¿Estoy en contradicción conmigo mismo?»(DA, TI, cap. VII, 257). 
poder. Saber valorar en cada contexto las condiciones necesarias y suficientes que hagan razonable y plausible un ejercicio democrático del poder exige una postura de moderado optimismo o de pesimismo moderado, que viene a ser lo mismo, respecto a las virtualidades democráticas, que, como advertía Tocqueville, no comparten quienes se empeñan en ejercer el "podemos» democrático de forma apriorística e inmoderada ${ }^{30}$. Cuando me refiera al tema de la religión, como una de las instituciones políticas más relevantes para Tocqueville, abundaré en esta cuestión.

Mayor vigencia tienen aún las propuestas concretas que, según Tocqueville, pueden socializar al individuo en la libertad impidiéndole así caer en la servidumbre voluntaria, vinculada tanto al materialismo como a la hybris del soberanismo despótico. Me refiero tanto a aquellas medidas que buscan afianzarse en el subsuelo de la sociedad política, como el asociacionismo o la participación, como a las medidas jurídicas e institucionales que limitan el poder, lo descentralizan, lo acercan a la vida cotidiana y, finalmente, lo legitiman. Especial importancia tiene la descentralización del poder, en particular del poder administrativo. La fórmula tocquevilliana de «desparramar el poder», distribuyéndolo, en los ámbitos «multilevel» de la política moderna, sigue siendo una garantía para el ejercicio auténtico y coherente de la libertad democrática.

El republicanismo democrático de nuestros días ha sabido dar razón de estas y de otras muchas aportaciones de Tocqueville a la construcción de nuestras sociedades democráticas, pluralistas y seculares. Estoy convencido de que buena parte de las razones antropológicas, epistemológicas, éticas y políticas que avalan la condición plural de las sociedades democráticas como un hecho y, a la vez, como un derecho - ser y deber ser- aparecen en la obra de Tocqueville. Cuestión relevante en su obra y de una enorme actualidad es la construcción del consenso democrático más allá del pluralismo desintegrador y del despotismo uniformizador. ¿Qué cohesiona a una sociedad secularizada

30 Una postura de moderado optimismo es la que sostiene E. GARZón VALDÉs, que exige, en primer lugar, conocer los argumentos del pesimista respecto a la «enfermedad republicana», como llamaba Tocqueville al dominio de la mayoría, (complejidad de las decisiones políticas y creciente dificultad de su control; crecimiento correlativo de la actitud de tutela de los gobernantes y del paternalismo jurídico-político, con el argumento de que hay que superar la «incompetencia básica» y la «estupidez popular» para garantizar la «infalibilidad popular»; lo poco que se toman en serio las restricciones constitucionales en países que se autoproclaman democráticos; lo que ha llegado a su fin no es la historia sino la política, que habría sucumbido ante las exigencias de la economía; además, otros argumentos de carácter externo: la decadencia del estado nación; el creciente autoritarismo internacional carente de transparencia y de control democrático; el 11-S y sus consecuencias, etc.). Garzón Valdés cree que lo más prudente tal vez sea adoptar un moderado optimismo o un pesimismo moderado, que es lo mismo, para alentar la esperanza de cumplir con un doble deber: el de vigilancia estricta de las posibles vaciamientos de las instituciones democráticas y el de pensar los ajustes que las democracias nacionales, consolidadas o no, requieren para enfrentar los peligros que denuncia el pesimismo moderado. (Ver Garzón Valdés, E., «Optimismo y Pesimismo en la democracia», en Claves de Razón Práctica. $\mathrm{N}^{\circ} 131$. Abril. 2003.) 
y pluralista evitando que caiga en la anarquía y en el despotismo? La respuesta a esta pregunta pasa por subrayar la importancia del capital social y de su generación; la decisiva importancia de las ideas y de los sentimientos, de los hábitos del corazón y de las costumbres, para que las instituciones funcionen adecuadamente, y viceversa.

\section{LA RELIGión COMO «INSTITUCIÓN POLÍTICA» RELEVANTE (TocoueVILle) ${ }^{31}$}

Tocqueville plantea la cuestión democrática en relación directa con el proceso de secularización, que él cree irreversible, pero oponiéndose con contundencia tanto al secularismo erastiano, profundamente arraigado en gran parte del imaginario francés, como a la que posteriormente se denominará la «teoría de la secularización», que, como sabemos, condena a la religión a la desaparición o, cuando menos, a su privatización y falta de significado en las sociedades modernas. Así, Tocqueville cuestionó, desde el principio, la supuesta «excepcionalidad americana», y adelantó bastantes de las posiciones que hoy son moneda común en la sociología de la religión. Lejos de ser una excepción, el caso de América será para Tocqueville un modelo a seguir en todo el mundo. El ejemplo norteamericano le servirá a Tocqueville tanto para justificar su convicción de que el contencioso europeo entre religión y sociedades democráticas es un proceso histórico de carácter contingente y particular, que no responde al proyecto de la providencia divina, como, sobre todo, para sacar a la luz las virtualidades sociogenéticas de la religión. Tocqueville reitera que la civilización angloamericana «es el producto - y este punto de partida debemos tenerlo siempre presente- de dos elementos completamente distintos, que en otras partes se hicieron a menudo la guerra, pero que, en América, se ha logrado incorporar en cierto modo el uno al otro, y combinarse maravillosamente: el espíritu de religión y el espíritu de libertad ${ }^{32}$. No es que Tocqueville sea tan ingenuo que no vea en ambos espíritus un potencial conflictivo, sobre todo, cuando el espíritu de libertad manifieste una impronta más secular que la del puritanismo de los orígenes, como fue el caso de algunos de los constituyentes y de una buena parte de ciudadanos norteamericanos. Pero será precisamente la forma en que se resuelve el conflicto el secreto del éxito. El omnipresente papel de la religión en la democracia americana será un ejemplo que Tocqueville utilizará para desautorizar aquellos procesos democráticos que se quieren construir desde inmanentismos cerrados a toda trascendencia y a concepciones de la soberanía popular de carácter absoluto.

31 Para un tratamiento más completo del tema, ver el ya citado Velasco, D., «Tocqueville (1805-1859), dos siglos después», de donde recojo algunos párrafos.

32 DA, T I, $1^{\text {a }}$ parte, 63-64: "Los norteamericanos confunden tan completamente en su espíritu el cristianismo y la libertad, que es casi imposible hacerles concebir el uno sin la otra; y no es entre ellos una de esas creencias estériles que el pasado lega al presente, que parece menos vivir que vegetar en el fondo del alma», 292 ; ver, asimismo, 293 ss. 
«¿Qué hacer de un pueblo, dueño de sí mismo, si no está sometido a Dios?» Este interrogante de Tocqueville se asocia con la cuestión de «la soberanía popular» como libertad de acción ilimitada y como tiranía de la mayoría o despotismo del poder centralizado. Ya hemos visto cómo Tocqueville rechazaba esta concepción de la soberanía popular de carácter absoluto y cómo desde una hermenéutica "trascendente» apelaba a la justicia como su límite necesario. La religión será para Tocqueville la institución imprescindible que permite a individuos y sociedades vincular la causa de la libertad a la de la «trascendencia», superando así con éxito las derivas totalitarias del principio de igualdad.

Se trata de ver la religión no como fundamento radicalmente externo del orden social, sino como un "cemento ideológico y cultural», como una «hegemonía moral y cultural» que permite a las sociedades encontrar el verdadero sentido último de la igualdad. La diferencia de la concepción tocquevilliana de la religión comparada con la «religión civil» de Rousseau es significativa, al respecto. Para Tocqueville, la concepción dialéctica de la historia humana, entendida como una cooperación entre Dios y los seres humanos libres, le lleva a afirmar, a la vez, la predilección divina por la igualdad y por las formas de organización sociopolítica que la favorecen, como la democracia, que adquieren así una legitimación religiosa, y la actitud crítica y escéptica respecto a la capacidad y posibilidad de que los seres humanos puedan construir sociedades democráticas igualitarias y viables, si no se ajustan a los criterios morales y religiosos que en el fondo inspiran y alimentan las auténticas realizaciones de lo humano. Esta relación dialéctica entre cosmovisión cristiana y liberalismo le lleva a Tocqueville a desechar las teorías del iusnaturalismo contractualista que se basan en un estado de naturaleza que él considera una mera ficción filosófica. Lo natural, lo religioso y lo histórico deben ser concebidos juntos, porque reflejan un mismo proyecto providencialmente querido y libremente asumido por los seres humanos. Lo que para Rousseau es una teoría iusnaturalista y racionalista de la igualdad humana, para él es un derecho natural que se origina en el hecho histórico y social del cristianismo.

Para Tocqueville, la ausencia de religión tiene efectos devastadores tanto en el individuo como en la sociedad, por lo que llega a afirmaciones tan rotundas como esta: «Semejante estado no puede menos que debilitar las almas, aflojar los resortes y preparar a los ciudadanos para la esclavitud... Yo dudo que el hombre pueda alguna vez soportar a un mismo tiempo una completa independencia religiosa y una entera libertad política; y me inclino a pensar que, si no tiene fe, es preciso que sirva, y, si es libre, que crea» ${ }^{33}$. Pero eso no quiere decir que la política y la democracia deban estar sometidas a la religión como ha sostenido el clericalismo de todos los tiempos. Ni siquiera se trata de que el Estado proteja a la religión o la haga popular por confortable y necesaria. Tocqueville es un liberal moderno que cree que el camino moderno puede ir de lo político a lo religioso pero no en sentido inverso, y que no es sometiéndose

33 DA T. II, parte 2 ${ }^{\text {a }}$, pág., p. 405. 
a alguna consigna venida de «más arriba», sino siendo lo más profundamente ella misma, mostrando a los hombres en dónde está su dignidad (en afrontar el futuro y la mortalidad), como la política («acción recíproca de los hombres entre sí») puede renovar los sentimientos y las ideas, engrandecer el corazón y el espíritu de los ciudadanos, mostrarles, de nuevo, por su misma realidad, por su eco en ellos, los caminos de la religión ${ }^{34}$. Para Tocqueville tan nefasto es vincular la religión al poder político como prescindir de su presencia y apoyo. Vincularla con el poder equivale a debilitarla y hacerla correr su misma suerte. Por eso defiende la separación de las Iglesia y el Estado, que ve como una exigencia para la verdadera cooperación entre el espíritu de la libertad y el espíritu de la religión.

Me parece que esta posición de Tocqueville sigue teniendo una gran vigencia en estos tiempos en los que las instituciones religiosas siguen empeñadas en actuar conforme al premoderno paradigma de los poderes (negociando concordatos y acuerdos jurídico-políticos), en vez de hacerlo desde el moderno «paradigma de los derechos y libertades» democráticos. Tocqueville advirtió con gran lucidez acerca de los graves y perniciosos costos religiosos y políticos que tare consigo la no diferenciación de dichos ámbitos. Sus páginas dedicadas al Islam fundamentalista tienen una agudeza y sentido profético indudables ${ }^{35}$. Hemos comenzado diciendo que Tocqueville plantea la cuestión democrática en relación directa con el proceso de secularización. Solamente sociedades seculares que no secularistas pueden evitar uniones ilegítimas entre religión y política, como las que se dan en algunos países de Europa, como la Francia que conoció Tocqueville ${ }^{36}$.

34 Thibaut, P., «Roussseau-Tocqueville. Un dialogue sur la Religión», en The Tocqueville Réview/La Revue Tocqueville, vol. XVIII, 1-1997: 47-95; número de 2005, 330-331.

35 Su primera reacción ante el Corán quedó contenida en una carta enviada a su primo Luis de Kergorlay, en marzo de 1838: «La doctrina de que la fe salva, que el primero de los deberes religiosos es obedecer ciegamente al profeta, que la guerra santa es la primera de todas las buenas obras..., todas estas doctrinas cuyo resultado práctico es obvio, se hallan en cada página y casi en cada palabra del Corán... Las tendencias violentas y sensuales del Corán chocan de tal modo a la vista que no concibo que escapen a un hombre con sentido común. (...) Mahoma ha ejercido sobre la humanidad un poder inmenso que creo, en definitiva, ha sido más perjudicial que provechoso».

«Mahoma hizo bajar del cielo, y dispuso en el Corán, no sólo doctrinas religiosas, sino máximas políticas, leyes civiles y penales y teorías científicas. El Evangelio no habla, por el contrario, más que de las relaciones generales de los hombres con Dios y entre sí. Fuera de ahí ni adoctrina ni obliga a creer nada. Solo por ello, entre otras mil razones, basta para mostrar que la primera de estas dos religiones no será capaz de predominar en épocas de luces y democracia, mientras que la segunda está llamada a regir en estos siglos y en todos los demás». DA TII, $1^{\text {a }}$ parte, cap. V.:406

36 Refiriéndose a los efectos perversos que en Europa se derivan de la unión ilegítima entre religión y política, dice así: «Los incrédulos de Europa persiguen a los cristianos como a enemigos políticos, más bien que como a adversarios religiosos: odian la fe como la opinión de un partido, mucho más que como una creencia errónea; y rechazan en el sacerdote menos al representante de dios que al amigo del poder. En Europa, el cristianismo ha permitido que 
Hay otras cuestiones relacionadas con la religión que Tocqueville aborda y que exigirían ser tratadas con mucho más detalle. Por razones obvias, concluyo estas páginas abordando una cuestión que subyace a toda su obra y que recojo bajo el epígrafe «pluralismo religioso, cohesión social y verdad» y que goza de gran actualidad.

Aunque personalmente creo que lo contrario a la verdad del ser humano no es el error, sino la violencia, hay una forma de tolerancia religiosa, que, con el encomiable objetivo de priorizar la paz sobre la verdad, me parece no tener en cuenta las exigencias de un espíritu reflexivo y crítico que no puede renunciar ni a dar razón de su fe ni a someter la verdad en la que cree a criterios un poco más coherentes con la autonomía racional que los del consenso entrecruzado. La cuestión de la verdad religiosa no se puede acotar a los parámetros marcados por su funcionalidad social. El pluralismo religioso no puede pretender que el creyente renuncie a explicitar la verdad que da coherencia formal y práctica a su praxis social. Otra cuestión será encontrar la forma menos inadecuada de explicitarla, conforme a las exigencias del pluralismo democrático. Ni para él, ni para la sociedad, sería suficiente un pluralismo demediado ${ }^{37}$.

Tocqueville barruntó algo de esto cuando dijo que en Estados Unidos había cierta patología a la hora de vivir la religión. Tocqueville, distingue, al respecto, dos situaciones: la de Estados Unidos, en donde se deja de creer en la religión verdadera, pero se la considera útil y se confiesa públicamente, pero desarrollando una cierta hipocresía (dado el peso de la opinión, se esconden los verdaderos sentimientos y dudas), por lo que la situación es ambigua; y la de Francia, en donde se abjura públicamente de la fe de los padres, provocando en los creyentes el odio a todas las ideas e instituciones modernas. Se da una guerra de opiniones, en la que todos van más allá de los «límites naturales»,

se le uniera íntimamente a los poderes de la tierra. Hoy día, esos poderes caen, y está como sepultado bajo sus restos. Es un cuerpo vivo al que se ha querido atar a cuerpos muertos: cortad los lazos que los retienen, y volverá a levantarse. Ignoro qué habría que hacer para devolver al cristianismo de Europa la energía de la juventud. Dios sólo lo podría; pero por lo menos depende de los hombres dejar a la fe el uso de todas las fuerzas que conserva todavía». DA T I , $2^{\text {a }}$ parte, p. 298.

37 En opinión de U. Beck, «hoy es decisiva para la supervivencia de la humanidad la pregunta sobre si se puede sustituir la verdad por la paz». El autor dice que, dado que las religiones instauran la fe como un distintivo absoluto y crean un abismo particular entre creyentes y no creyentes; y dado que los dioses monoteístas y sus verdades absolutas establecen categorías condenatorias y excluyentes, amenazando con una nueva era oscurantista, hay que posibilitar un modelo de tolerancia interreligiosa, que no tenga como objetivo la verdad sino la paz, y apuesta por él. Se trataría de una transición «del monoteísmo de la religión hacia el politeísmo de lo religioso bajo el signo del "dios personal"». Una «tolerancia del sincretismo» que evitaría los dos errores que, según Berger, a quien menciona citando, a su vez, al filósofo japonés Nakamura, son el monoteísmo y el principio de contradicción de Aristóteles. "Cualquier persona inteligente en Asia sabe que existen muchos dioses y que las cosas pueden ser a la vez A y no A».

(BЕск, U., «Dios es peligroso». El País, 12/01/2008) 
confundiendo lo religioso y lo político, lo que no es natural ${ }^{38}$. La posición de Tocqueville consiste, por tanto, en defender la separación de las Iglesias y del Estado, de lo religioso y de lo político, argumentando que la utilidad política de la religión depende de la vinculación auténtica y puramente religiosa de cada hombre a su religión y no de su instrumentalización política funcional. La religión de los americanos pierde su utilidad en la proporción en que se vinculan a ella en razón de esta utilidad. Pero, esta posición de Tocqueville encubre algunas ambigüedades y contradicciones, que él formula, pero que no resuelve adecuadamente. Su argumentación consiste en decir: «Si sirve mucho al hombre que su religión sea verdadera, no sucede lo mismo en cuanto a la sociedad. La sociedad no tiene nada que temer ni que esperar de la otra vida; y lo que importa más, no es tanto que todos los ciudadanos profesen la verdadera religión, sino que profesen una religión ${ }^{39}$. No se puede pretender, a la vez, mantener la utilidad de una religión, a la que se le vacía de su verdadera fuerza vinculante, que es la convicción del creyente de que lo que cree es verdadero y, por tanto, religante, ya que en ello le va a uno la salvación eterna, y no una mera convención social que es necesario respetar, como hacían los patricios romanos con las creencias de los plebeyos para asegurarse así su obediencia. Si se impone la hipocresía, lo que de verdad acaba sustituyendo a la religión es una forma de pensar mayoritaria, una opinión publica que utiliza la religión para sofocar despóticamente la libertad de opinión y de creencias.

Creo que, en este sentido, lleva razón P. Manent, cuando afirma que hay un equívoco tocquevilliano en el papel de la religión para fundamentar la democracia, ya que si, por un lado, la considera la primera de las instituciones políticas de los americanos, por otro, encuentra en la religión el ejemplo del desorbitante poder social de la democracia sobre el espíritu humano y sobre la libertad intelectual. Si antes hemos hablado de la religión como la brida saludable del caballo, ahora, hay que hablar, también, de que el caballo democrático tiene la mordaza en los dientes. En el caso del cristianismo americano, no es el dogma el que es opinión común, sino la opinión común la que es dogma. La separación de las Iglesias y del Estado sería entonces una ilusión, ya que la religión está sometida al régimen democrático. La explicación vendría dada por la historia de la democracia americana. Tocqueville juzga que el destino de la República americana ha estado ampliamente determinado por el carácter de su fundación puritana, ya que el puritanismo significa la confusión de lo religioso y de lo político ${ }^{40}$.

Son muchas las cuestiones que el pluralismo religioso plantea, hoy, a las mismas religiones y a las sociedades democráticas. Concluyo mi reflexión formulando algunas, que espero sirvan para enriquecer nuestro debate. ¿Considerar a la religión como seña de identidad, de pertenencia y de cohesión social,

38 DA, T I, $2^{\text {a }}$ parte: 290 ss. Ver Velasco, D., «Tocqueville (1805-1859), dos siglos después», 183-250, en especial, pp 231-240.

39 DA, Ibid., p. 90.

40 Manent, P., Tocqueville et la nature de la democratie. Paris. Julliard, 1982, 130 ss. 
en sociedades plurales y seculares, es algo anacrónico y antidemocrático o es una forma legítima de adaptación al nuevo contexto de pluralismo radical? ¿Lo que pone en riesgo el respeto al pluralismo es un laicismo inmanentista y ateo que se impone como «religión civil» (acusación que vienen haciendo algunas jerarquías eclesiásticas) o, más bien, el rechazo del pluralismo viene de una perversión del lazo teológico-político convertido en instrumento de particularismos políticos excluyentes, etnoculturales y religiosos (como ocurre con ciertas posiciones tradicionalistas católicas o con ciertas ideologías políticas que utilizan al cristianismo como «religión civil» frente al Islam y otras religiones). "¿Paz, sin Verdad? La "abstinencia epistémica” y "la religión en los límites de la razón». ¿Una nueva emergencia de lo trascendente que prioriza lo religioso o una desacralización de lo inmanente que prioriza lo político?

Universidad de Deusto

Demetrio Velasco

dvelasco@deusto.es

[Artículo aprobado para publicación en diciembre de 2015] 